\title{
RIGHT TO INFORMATION IN DISASTER SITUATIONS AND LOCAL INFORMATION NETWORKS
}

\author{
Dhanushi Senanayake \\ G:/144//13 O (1002
}

Master of Arts Degree in Mass Communication University of Sri Jayawardanepura 
Thesis submitted to the Department of Mass Communication, University of Sri Jayawardanepura in partial fulfillment of the requirements of the Master of Arts Degree examination in Mass Communication.

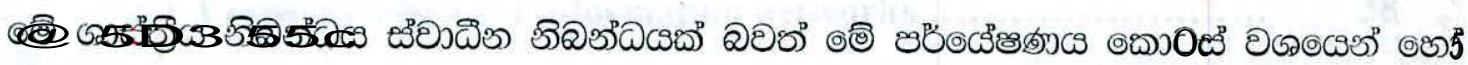

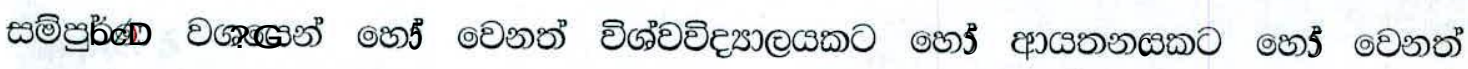

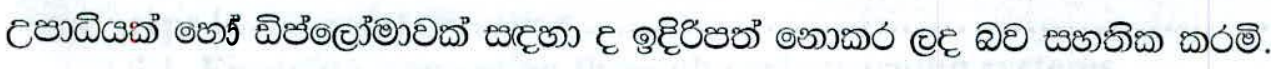
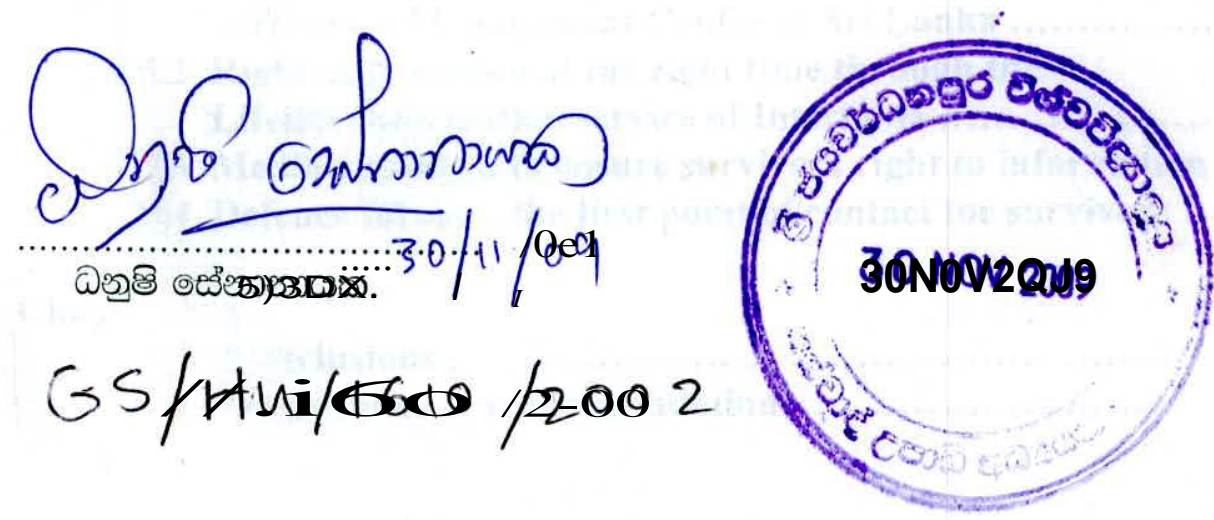


\section{ACRONYMS}

DMC - Disaster Management Centre

GN - Grama Niladhari (GN)

ICTs - Information Communication Technologies

IDPs - Internally Displaced Persons

$\mathrm{MOH}$ - Ministry of Health

NGO - Non-governmental organisation

PHI - Public Health Inspector

SIFFS - South Indian Federation of Fishermen Societies (SIFFS) is a non governmental organization (NGO) working in the marine fisheries sector.

SNEHA- Sneha is a voluntary organisation founded in 1986 to cater to the befriending needs of the lonely, desperate and the suicidal

UN - United Nations 


\section{ACKNOWLEDGEMENTS}

I am very gratful to all who helped me in a number of ways to make this thesis a reality. If not for the support and encouragement of my husband - Kolitha and my family it would not have been possible for me to attmept and complete this thesis.My special thank you is also extended to Madumali and Sandamali at Internt Kade who helped me to take the print outs of this report.

It was my batch mate Ananda Jayasekera who directed me to identify a topic such as this and helped me to find background information whom I thank first and foremost.

I am very much thankful and appreciate the cooperation and valuable inputs provided to me by Mr Menaka Wijesinghe from the Disaster Management Centre, Ms Fiona Barton from Internews, and my friend Captain N.S.B Piyasena from Sri Lanka Red Cross, and the Village Disaster Management Committee representatives from Katepola GN division in Ratnepura district.

The sincere support provided to me by my ex colleague Tushani Kalugalgedera by doing an excellent job of editing for which am very grateful. 
RIGHT TO INFORMATION IN DISASTER SITUATIONS AND LOCAL INFORMATION NETWORKS

Dhanushi Senanayake

\section{EXECUTIVE SUMMARY}

In a context where the space is shrinking even for the activists or media for

deliberations on right to information; this study adds a dimension- communities affected by disasters. This study explores the prevailing situation in Sri Lanka related to right to information regime as spelt out in the legislation: with emphasis on disaster situations, the role of information for communities at risk and other key players involved in disaster risk management.

Rationale: In disaster situations access to information at the right time can not only save lives but reduce the expenses on relief provisions and save money for development and even stop corruption and mal practices. Further, poor and marginalized communities who are more vulnerable to disasters could be made more resilient by ensuring their right to information and making them an informed community and the disaster management processes could thereby benefit from an environment when right to information is possible.

Objective: This study aims at highlighting the gaps and best practices and the role of local information networks for communities' access to information in disasters and recommends a model that addresses such gaps and lessons from the best practices. 


\section{Conclusion and recommendations}

In Sri Lanka denial of the right to information and freedom of expression has been the norm and no changes can be expected during disaster situations as media freedom, the public's right to know, and the individual's fundamental rights to freely hold and express opinions are taken for granted.

In order to establish right to information of survivors and communities at risk to disasters there has to be legal reforms and systems in place within media and humanitarian organisations for implementation by the government and application of the right to information by the public including marginalised groups.

\section{Recommendations}

At every stage of the post disaster response efforts must be made to actively share all relevant information with survivors.

Assigned information officers from government and humanitarian organisations need to proactively share information and use appropriate language and formats with communities at risk to disasters.

In the provision of information the different needs of marginalised groups such as elderly, children, disabled and women has to be taken into account.

Provide a climate in which free media can operate and encourage community media initiatives. 


\section{CHAPTER 1}

\section{INTRODUCTION}

Today disasters in the form of floods, cyclones, tornadoes, landslides, droughts, and epidemics have become almost a common day occurrence all over the world. While a majority of the population in South Asia live in abject poverty it has also become a hotspot for disasters resulting in the severe loss of life and resources. It is often the poor and marginalised communities in South Asia, including Sri Lanka, who are most vulnerable to disaster situations. They lack the capacity and resources to deal with disasters and recover from them effectively.

Poor and marginalised communities often live and depend on fragile resource bases for their livelihoods. These include coastal areas which are subject to coastal erosion and vulnerable to tsunamis as well as flood plains and hilly areas which are subject to landslides. These communities, although aware of the imminent danger to their lives, continue live in the same areas as they do not have diversified livelihoods to do otherwise. After a disaster these communities have neither the bargaining power nor the community governance structures to ensure they receive the required services or assistance. They are unable to demand for their share of allocated relief from the Ministry of Social Services or to question the Meteorological Department for not detecting signs of an impending disaster or not issuing early warnings in time for people to evacuate.

The lack of accurate information, lack of community awareness on their right to information and the lack of effort from support organisations to address this situation 
awareness among development agencies and media in relation to the right to information of survivors of disaster situations but also lack of a vision to ensure this right.

\subsection{Objective}

This research report aims to explore the current situation in relation to communities affected by disasters and argues for strengthening the protection and promotion of disaster affected populations' right to know and right to be heard. The importance of ensuring the survivors' right to information and the vital contribution it could make to strengthen disaster management processes is elaborated in the report. While hoping this report will benefit the efforts of civil society organisations and journalists who are striving to create an environment that will put affected populations at the heart of disaster management work, I also firmly believe this will add to the growing awareness regarding the denied rights of affected communities in Sri Lanka and the world over.

\subsection{Terminology}

\section{Right to information of survivors and communities prone to threats from disasters}

In the immediate aftermath of a disaster situation survivors are provided relief items that comprise of food, clothes and other basic needs by organisations and individuals who come with the good intention of helping the affected communities.

Survivors of disasters also need information on whether their near and dear ones are alive or dead, reassurance of whether there are chances of the disaster reoccurring and 
that they are housed in a safe area, whether children can or cannot go to the nearby school, whether the people in camps can go back to their former livelihoods, who is planning to help resettlement, and information on the allocation from the government Department of Social Welfare as reimbursement for communities affected by disasters.

Survivors need to have access to a credible and acceptable source of media such as news broadcasts on radio, newspapers, etc. Furthermore, survivors also need to have access to relief providing organisations and organisations involved in resettlement and rebuilding to give feedback on the type of relief or rebuilding measures provided to them.

Disaster situations - A natural hazard or hazard triggered due to human activity that negatively impacts on a particular community is considered a disaster. Disaster situations have three stages - namely pre, during and post disaster situations. Disasters can bring about a loss of lives, property and infrastructure, as well as destroy resources that are necessary for people's livelihoods, education, etc. Formal information channels such as telephones and media are often disrupted or cannot be accessed during disaster situations. However, for the survivors the need for information is as critical as essential items such as food, water, sanitation etc. The amount of information and areas on which information is required during a disaster is much greater than under normal circumstances.

Local information networks - Local information networking can take place on a formal basis or can be informal in nature where community leaders get together for a 
common purpose or to confront a common enemy such as a disaster that is likely to affect them. These associations can have a greater impact within the areas they operate than even other factors such as media. Furthermore, these associations could also serve as the link between external actors and the affected communities. Local information networks play a crucial role before, during and after a disaster when the affected communities do not have access to the accepted formal information channels such as telephones, newspapers, radio, etc.

Local information networks employ different types of tools and approaches for the dissemination of information. Some of these tools include the modern Information Communication Technologies (ICTs) which are used extensively by formal networks. They also use traditional tools (such as rituals, folk songs, chants) used by more informal networks.

\subsection{Survivors' right to information in disaster situations}

Natural and man made disasters since 2004 show a trend of resulting in an increased loss of lives, destruction of infrastructure, hampering essential services and leaving many displaced all over the globe. Sri Lanka too has had its fair share of impacts from disasters.

Humanitarian organisations ${ }^{1}$ involved in providing relief and attending to rehabilitation and restoration work have prioritised and identified that they need to go beyond the

An organisation concerned about human welfare, especially as manifested through philanthropy. 
mere provision of relief and rebuilding of infrastructure. There needs to be a shift towards strengthening the resilience of the communities vulnerable to disasters.

Humanitarian agencies, governments, and media often tend to see communities affected by disasters as helpless victims. Nevertheless in disaster situations affected communities have demonstrated immense strength to cope with the disaster situation and possess knowledge about coping in such adverse situations.

The perception of affected communities as passive recipients of relief does not help communities to recognise their strengths or to take part in reconstruction efforts and get back to their livelihoods. The present approach to disaster relief and rehabilitation work does not provide much information to humanitarian and other interested organisations about the actual needs and capacities of communities. In addition, it does not give affected communities an opportunity to obtain information regarding their missing relatives, how much they are entitled to as relief and where their houses are to be rebuilt. Therefore, it is vital that there is a conducive situation that allows for the free flow of information between communities, aid workers, the government and the media.

While the correct information at the relevant time can save lives in the wake of a disaster it is also capable of assisting in quick recovery. Having access to information can help affected communities trace their lost family and friends, know how much compensation they are entitled to or where they are going to live, and helps in simply understanding why a disaster struck. Such information means a lot to survivors left homeless and traumatised. 
The free flow of information and the right to expression and to seek and receive information held by public bodies can be categorised as the right to information. The right to information has been subject to debate and discussed globally as well as in Sri Lanka. Right or access to information has been recognised as a human right since 1946. Article 19 of the Universal Declaration of Human Rights ${ }^{2}$ (1948) and Article 19 of the International Covenant of Civil and Political Rights ${ }^{3}$ (1966) recognise the right to seek, impart and receive information as part of the fundamental right to freedom of speech and expression. The constitution of the Democratic Socialist Republic of Sri Lanka also recognises this right as per Article 14(1), (a).

\subsection{Who does what, where, when, and for whom?}

In the case of governments, and even development or relief agencies, there is a tendency to not disclose or to even conceal certain information which could expose instances of negligence or the misappropriation of funds. Media on the other hand tend to overstate the casualty and loss figures and the extent of the crisis. The absence of legal and formal frameworks to access official information in many South Asian countries, with the exception of India, hampers transparent reporting of the disasters. In Pakistan and Sri Lanka the Official Secrets Act and the Prevention of Terrorism Act ${ }^{4}$ strategically control and conceal information from the public and disaster affected communities. In such situations journalists tend to bank on informal and personal connections to obtain information. This may have strong consequences (regarding accuracy of information provided) on 'at risk' communities.

\footnotetext{
On December 10, 1948 the General Assembly of the United Nations adopted and proclaimed the Universal Declaration of Human Rights in order to ensure the protection of rights of all humans.

The International Covenant on Civil and Political Rights (ICCPR) is a multilateral treaty adopted by the United Nations General Assembly

Prevention of Terrorism Act of $\mathbf{1 9 7 8}$ is a law in Sri Lanka. It provides the police with broad powers to search, arrest, and detain suspects
} 


\subsection{The present context that needs a shift}

Victims of a disaster want to unite with their families and need assistance in terms of temporary shelter, sanitation, food and housing. What often happens is that people are informed but not consulted when there is an onset of a disaster with regard to the provision of relief, resettlement and rehabilitation.

In a disaster situation, for certain functions the government machinery is expected to take the lead. It is the government that has to proclaim that a disaster has affected a particular location. It is the government that has to direct government relief mechanisms and issue statements to the media about the deaths and missing persons. However, exceptions to this could be observed in the immediate aftermath of the 2004 tsunami where Sri Lankan media and other civil society actors assumed leadership in informing people about deaths and missing persons and what relief items were needed where.

Generally, the tendency is for media reporting to be done using an event based approach $^{5}$. Media reports highlight stories about victims and survivors. These types of stories tend to be highly sensationalised and therefore can have negative impacts on the affected communities and relief efforts. In 2001, Hambantota District was not only affected by a severe drought but was also flooded with non degradable plastic water bottles that came as relief due to the sensationalising of the drought in reporting by Sirasa (a local television channel), and local radio channels and print media. The problem with such stories is that the victims are portrayed as helpless - as lacking the knowledge and capacity to become part of the rebuilding process. Another common

\footnotetext{
5 Unstructured data gathered from sources of intelligence of any nature.
} 
function that government and humanitarian agencies expect from media is to be a propaganda arm of the relief and rehabilitation efforts. For instance, huge amounts of money were directed towards getting media organisations to feature the rebuilding activities of the humanitarian organisations that operated in Sri Lanka. This is money which could have been channelled more effectively towards the actual rebuilding process.

Humanitarian organisations, government authorities and social welfare organisations contribute in providing information to the affected communities who are living in disaster prone areas. This information is provided in order to generate community awareness about scientific reasons as to why certain disasters (such as floods, tsunami, and hazard, lightening) occur and about disaster prevention and preparation. These were developed in the form of posters, radio programmes, videos and so on. However, there were no instances of such informative education material creating an impact in terms of saving lives. The main reason for this was the failure to get the messages internalised by the targeted community.

However, there are also instances where due to active engagement and enabling the two- way flow of information through awareness programmes there were lasting positive impacts. Lakbima ${ }^{6}$ reported of an incident in 2008 where a student of a school had been able to save the lives of other children and teachers who would have been

6 A sinhala mainsteam newspaper whcih has a daily and a weekend issue. 
affected by a landslide. The student had learnt about the warning signs of an impending landslide from an awareness programme organised by Save the Children ${ }^{7}$.

While the government and humanitarian organisations request the media to publicise their relief and rehabilitation efforts, there are instances where the government has denied media and/or humanitarian organisations access to particular sites or to interview survivors, etc. Governments sometimes fear that the media would highlight their negligence or that the humanitarian organisations' media may report about gaps in their processes. A classic example is the Sri Lankan governments' denial of access to journalists to visit the Internally Displaced Persons (IDPs) in Menik Farm in Vavuniya, Jaffna District, who were displaced by the war and affected by floods recently.

Thus, it is clear that although information itself is a vital form of aid, its potential is not properly understood nor is it paid due emphasis in disaster management. The existing disaster management mechanisms of governments and humanitarian organisations are reluctant to consider affected communities as having the capacity to contribute to speedy recovery efforts and this undermines the role of local information networks. The local information networks possess indigenous knowledge on disseminating early warning signs of an impending disasters and coping with situations where there is limited access to resources. Furthermore, these information systems are linked to a central location in a village, such as the temple or village school, and contain unwritten rules which form part of the system. Some of these unwritten rules include ensuring the protection of life and dignity of vulnerable groups such as children, women, the elderly

\footnotetext{
7 An international children's charity based in the UK which supports both emergency and long-term relief and development projects.
} 